\title{
A Study Of Personality Traits And Attachment In Romantic Relationships Among Normal Weight, Overweight And Obese Adults
}

\author{
Chowdhury $\mathbf{S}^{1}$, Mukherjee $\mathbf{T}^{2}$ \\ 1. MPhil Scholar, University of Calcutta, Kolkata, India 2. Associate Professor, Department of \\ Psychology, University of Calcutta, Kolkata, India
}

E-mail *Corresponding author: tilottamamukherjee3@gmail.com

\begin{abstract}
Introduction: Obesity has significant physical and psychological implications along with severe impacts on social and interpersonal relationships of individuals. The present work is a comparative study between normal weight, overweight and obese individuals with respect to their personality traits and attachment in romantic relationships, it also aims to explore the relationship of body mass index with the variables chosen.
\end{abstract}

Material And Method: The total sample size was 90. The study was conducted upon three groups-the three groups consisted of 30 normal weight participants, 30 overweight participants and 30 obese participants each. Participants were grouped on the basis of their Body Mass Index (BMI)- which was calculated from self-reported measures of height and weight. All participants were administered the NEO-Five Factor Inventory and the Experiences in Close Relationships- Revised Questionnaire. On the basis of the obtained data, an Independent Samples t-test was done to see if there existed any significant difference between the groups. A Pearson's coefficient correlation was performed for the total sample and a Stepwise multiple regression analysis was performed to see if any of the variables were significant predictors of BMI for the present sample.

Results: Significant differences existed between the groups in case of neuroticism, extraversion, openness and conscientiousness. The BMI of adults in the present sample has a significant positive correlation with openness and anxious attachment in romantic relationships and a significant negative correlation with extraversion and conscientiousness. Openness and conscientiousness were also significant predictors of BMI for the present sample.

Conclusion: The study adds significant findings to the interaction of obesity with the big five personality traits and sheds light on how attachment in romantic relationships is often affected by the weight stigma.

Keywords: BMI, extraversion, openness, conscientiousness, anxious attachment.

\section{INTRODUCTION}

Obesity is a grave public health problem not only increasing the risk of physical illness but also burdening obese individuals with severe psychological consequences. As per the estimates of the World Health Organisation (WHO), obesity has touched epidemic proportions worldwide, where more than one billion adults are overweight and 300 million of them clinically obese. ${ }^{1}$ The primary outcome measure which is used for assessment of overweight or obesity is the Body Mass Index of an individual (BMI). Dividing the body mass(weight) of an individual by the square of the body height gives the BMI value of an individual which is universally expressed in units of $\mathrm{kg} / \mathrm{m}^{2}$. Guidelines for diagnosis of obesity and abdominal obesity for the Indian population have been revised and published in the Journal of the Associations of Physicians of India (JAPI). ${ }^{2}$ The categories are as follows Underweight- $\left(<18.5 \mathrm{~kg} / \mathrm{m}^{2}\right)$, Normal weight$\left(18.5-22.9 \mathrm{~kg} / \mathrm{m}^{2}\right)$, Overweight- $\left(23-24.9 \mathrm{~kg} / \mathrm{m}^{2}\right)$, Obese $\left(\geq 25 \mathrm{~kg} / \mathrm{m}^{2}\right)$.

Personality traits are consistently associated with the controllable behaviours that lead to obesity $^{3}$, and personality has an effect on adiposity even after controlling for known demographic and genetic influences. ${ }^{4}$ Studies in the past have focused on the relationship between obesity and the Big Five traits of Personality. Several studies have observed 
elevated scores of neuroticism in individuals with obesity from the general population $5,6,7$ suggesting a positive association between neuroticism and BMI. Some studies have suggested that the conscientiousness domain of personality, comprising sub-facets such as selfdiscipline and order, is a predictive factor for overweight and obesity. $6,7,8$

Research have also focussed on finding whether obesity tends to affect an individual's intimacy or attachment with their partner. Mukhopadhyay, 20089, in his work found obese women are less likely to marry or cohabitate than non-obese women. Due to the stigma associated with excess body weight, individuals do feel that obesity might affect the relationship they have with their partner. Studies have shown that compared to average-weight peers, overweight adolescents were less likely to have dated and were more dissatisfied with their dating status. ${ }^{10}$

The present work is a comparative study between obese, overweight and normal weight individuals with respect to their personality traits and attachment in romantic relationships. It also seeks to explore the relationship of body mass index (BMI) with personality traits and attachment in romantic relationships among normal weight, overweight and obese adults.

\section{MATERIAL AND METHOD}

Adults ranging from 20-30 years of age, who were at the time of this research, involved in a romantic relationship in their lives were selected for this study. The total sample comprised of 90 subjects, divided into 3 groups having 30 participants in each. The participants were classified into the groups in terms of their BMI, where one group had 30 participants with a BMI ranging from (18.5-22.9) $\mathrm{kg} / \mathrm{m}^{2}$, and were classified as the Normal Weight Group. The second group had 30 participants with a BMI ranging from (23-24.9) $\mathrm{kg} / \mathrm{m}^{2}$ and were classified as the Overweight Group, the third group had 30 participants with a BMI of $(\geq 25)$ and were classified as the Obese Group. The data was collected from gyms, fitness centres and diet clinics across the city of Kolkata, over a period of 6 months. Convenience sampling method was used for the present study to approach the participants. The subjects were first explained about the purpose of the present study which was followed by obtaining written consent from all the participants.

The BMI of the participants were calculated from the self-reported measures of weight and height and they were accordingly classified into one of the three groups mentioned above. The height and weight measures of the participants were cross checked with their fitness report charts present in the gyms and diet clinics that were weekly updated with their height and weight measures. Following this, all participants in all three groups were administered a predetermined set of questionnaires for obtaining the information necessary for the present study. Appropriate relevant safeguards in relation to the protection of subjects had been undertaken and reviewed by an ethical review committee at the University for the current study. The research was conducted following general ethical guidelines in psychology.

Participants within the age range of 20-30 years were selected for this study as the last decade has seen a rise in overweight and obesity among young adults, especially college and university students. ${ }^{11}$ Added to that many young adults also undergo significant lifestyle changes such as leaving home, starting new jobs or higher studies, developing romantic relationships, These are significant transitions in their life course, that may have deeper social and psychological consequences. ${ }^{12}$

Inclusion Criteria included: all the participants belonged to the age range of 20-30 years, all the participants were involved in a romantic relationship for a minimum of 6 months.

Exclusion criteria included: Individuals with a BMI of less than $18.5 \mathrm{~kg} / \mathrm{m}^{2}$ were not included in the study, Individuals below 20 years and above 30 years of age were not included in the study, Married individuals were not included in the present study

The objectives of the present study were: i) To study the significant differences if any, between the groups (normal weight-overweight, overweight-obese and normal weight-obese) with respect to personality traits and attachment in romantic relationships ii) To study the correlation of BMI with the psychological measures taken - that is personality traits and attachment in romantic relationships iii) To study if any of the variables were significant predictors of BMI for the present sample 
The Neo-Five Factor Inventory (Neo-FFI) was used as a measure of personality in the present study. The NEO FFI is a 60 -item version of The Revised NEO Personality Inventory (NEO - PIR) that provides a brief and comprehensive measure of the five domains of personality (Neuroticism, Extraversion, Openness, Agreeableness and Conscientiousness.) It consists of the five 12 - item scales that measure each domain. ${ }^{13}$ Each of the five domains of the NEO FFI has been found to possess adequate internal consistency and temporal stability $(\alpha=$ .68 to $.86 ; r=.86$ to .90$).{ }^{13,14}$ The validity measures report correlations of $.75-.89$ for the NEO-FFI. ${ }^{15}$ The Experiences in Close Relationships-Revised (ECR-R) was used as a measure of attachment in romantic relationships in the present study. ECR-R was designed to assess differences among individuals with respect to attachment-related anxiety and attachment-related avoidance. The scale consists a total of 36 items and measures attachment on the scales of anxiety and avoidance. The first 18 items in the questionnaire comprise the attachment-related anxiety scale. Items $19-36$ consist of the attachment-related avoidance scale. The estimate of internal consistency reliability tends to be .90 for the two ECR-R scales. Both ECR-R subscales demonstrated strong convergent and discriminant validity 16,17 All the tests were administered by the researcher to make sure that the subjects understood each item properly and that no item was omitted or left incomplete. Following data collection, responses were scored according to the standard procedures given in the manuals and Statistical analysis was done by computing the means, standard deviations (SDs) for the scores. The obtained data was then analysed by means of Independent Samples t-test to see if there were significant differences between the groups chosen. To find out the nature of relationship of body mass index and the psychological measures taken -the Pearson's coefficient correlation was computed for all the three groups and the Stepwise multiple regression analysis was performed to see if any of the variables were significant predictors of BMI for the present sample.

All the statistical computations were conducted using SPSS 16.0 (SPSS, 2007).

\section{RESULT}

The results obtained by the statistical computation have been mentioned in the following table.

Table 1: Comparison between the normal weight-overweight, overweight-obese, normal weight-obese groups with respect to personality traits (Neuroticism, Extraversion, Openness, Agreeableness and Conscientiousness) and Attachment in romantic relationships (Attachment-Anxiety, Attachment-Avoidant)

\begin{tabular}{|c|c|c|c|}
\hline Measures & Groups Measured & Mean (SD) & $\mathrm{t}(58)$ \\
\hline \multirow{3}{*}{ Neuroticism } & $\begin{array}{l}\text { Normal weight } \\
\text { Overweight }\end{array}$ & $\begin{array}{l}25.06(7.43) \\
22.20(8.01)\end{array}$ & 1.437 \\
\hline & $\begin{array}{l}\text { Overweight } \\
\text { Obese }\end{array}$ & $\begin{array}{l}22.20(8.02) \\
27.06(7.15)\end{array}$ & $-2.481^{*}$ \\
\hline & $\begin{array}{l}\text { Normal weight } \\
\text { Obese }\end{array}$ & $\begin{array}{l}25.06(7.43) \\
27.06(7.15)\end{array}$ & -1.063 \\
\hline \multirow{3}{*}{ Extraversion } & $\begin{array}{l}\text { Normal weight } \\
\text { Overweight }\end{array}$ & $\begin{array}{l}30.00(5.12) \\
29.23(6.37)\end{array}$ & 0.514 \\
\hline & $\begin{array}{l}\text { Overweight } \\
\text { Obese }\end{array}$ & $\begin{array}{l}29.23(6.36) \\
26.13(6.40)\end{array}$ & 1.881 \\
\hline & $\begin{array}{l}\text { Normal weight } \\
\text { Obese }\end{array}$ & $\begin{array}{l}30.00(5.12) \\
26.13(6.40)\end{array}$ & $2.583^{*}$ \\
\hline \multirow{3}{*}{ Openness } & $\begin{array}{l}\text { Normal weight } \\
\text { Overweight }\end{array}$ & $\begin{array}{l}25.90(5.71) \\
29.57(5.70)\end{array}$ & $-2.490^{*}$ \\
\hline & $\begin{array}{l}\text { Overweight } \\
\text { Obese }\end{array}$ & $\begin{array}{l}29.57(5.70) \\
29.77(4.86)\end{array}$ & -0.146 \\
\hline & $\begin{array}{l}\text { Normal weight } \\
\text { Obese }\end{array}$ & $\begin{array}{l}25.90(5.71) \\
29.77(4.86) \\
\end{array}$ & $-2.825^{*}$ \\
\hline \multirow{3}{*}{ Agreeableness } & $\begin{array}{l}\text { Normal weight } \\
\text { Overweight }\end{array}$ & $\begin{array}{l}23.83(3.46) \\
24.06(4.63) \\
\end{array}$ & -0.221 \\
\hline & $\begin{array}{l}\text { Overweight } \\
\text { Obese }\end{array}$ & $\begin{array}{l}24.06(4.63) \\
24.20(4.19)\end{array}$ & -0.117 \\
\hline & $\begin{array}{l}\text { Normal weight } \\
\text { Obese }\end{array}$ & $\begin{array}{l}23.83(3.46) \\
24.20(4.19)\end{array}$ & -0.369 \\
\hline \multirow{3}{*}{ Conscientiousness } & $\begin{array}{l}\text { Normal weight } \\
\text { Overweight }\end{array}$ & $\begin{array}{l}32.43(5.60) \\
30.63(6.78)\end{array}$ & 1.089 \\
\hline & $\begin{array}{l}\text { Overweight } \\
\text { Obese }\end{array}$ & $\begin{array}{l}30.63(6.78) \\
28.90(7.10)\end{array}$ & 0.967 \\
\hline & $\begin{array}{l}\text { Normal weight } \\
\text { Obese }\end{array}$ & $\begin{array}{l}32.43(5.60) \\
28.90(7.10)\end{array}$ & $2.083^{*}$ \\
\hline \multirow{3}{*}{ Attachment Anxiety } & $\begin{array}{l}\text { Normal weight } \\
\text { Overweight }\end{array}$ & $\begin{array}{l}2.89(0.92) \\
2.86(1.05)\end{array}$ & 0.099 \\
\hline & $\begin{array}{l}\text { Overweight } \\
\text { Obese }\end{array}$ & $\begin{array}{l}2.86(1.05) \\
3.28(1.05) \\
\end{array}$ & -1.518 \\
\hline & $\begin{array}{l}\text { Normal weight } \\
\text { Obese }\end{array}$ & $\begin{array}{l}2.89(0.92) \\
3.28(1.05) \\
\end{array}$ & -1.513 \\
\hline \multirow{3}{*}{$\begin{array}{l}\text { Attachment } \\
\text { Avoidance }\end{array}$} & $\begin{array}{l}\text { Normal weight } \\
\text { Overweight }\end{array}$ & $\begin{array}{l}2.62(0.81) \\
2.48(0.82)\end{array}$ & 0.684 \\
\hline & $\begin{array}{l}\text { Overweight } \\
\text { Obese }\end{array}$ & $\begin{array}{l}2.48(0.82) \\
2.78(1.09) \\
\end{array}$ & -1.200 \\
\hline & $\begin{array}{l}\text { Normal weight } \\
\text { Obese }\end{array}$ & $\begin{array}{l}2.62(0.81) \\
2.78(1.09)\end{array}$ & -0.23 \\
\hline
\end{tabular}


The findings in table 1 reveal that for Neuroticism, a significant difference exists between the Overweight and Obese groups, with the latter having a higher mean score. A significant difference also exists between the Normal Weight and Obese groups for Extraversion, with the former group having a higher mean score. For the dimension of Openness, a significant difference exists between the Normal Weight and Overweight groups as well as the Normal Weight and Obese groups, with the Overweight and Obese group having the higher mean scores. A significant difference also exists between the Normal weight and Obese groups with respect to the dimension of Conscientiousness with the Normal Weight and Obese groups having the highest and lowest mean scores respectively.

Table 2: Pearson product moment coefficient of correlation(r) between Body Mass Index and each of the measures considered in the present study for the total sample ( $N=90)$

\begin{tabular}{|l|l|l|}
\hline \multicolumn{3}{|c|}{ Body Mass Index (BMI) } \\
\hline Variables & $\begin{array}{l}\text { Correlation } \\
\text { Coefficient }\end{array}$ & $\begin{array}{l}\text { Level Of } \\
\text { Significance }\end{array}$ \\
\hline Neuroticism & 0.161 & 0.130 \\
\hline Extraversion & -0.230 & $0.029^{*}$ \\
\hline Openness & 0.287 & $0.006^{* *}$ \\
\hline Agreeableness & 0.024 & 0.825 \\
\hline Conscientiousness & -0.216 & $0.041^{*}$ \\
\hline $\begin{array}{l}\text { Attachment- } \\
\text { Anxiety }\end{array}$ & 0.211 & $0.046^{*}$ \\
\hline $\begin{array}{l}\text { Attachment- } \\
\text { Avoidance }\end{array}$ & 0.123 & 0.249 \\
\hline \multicolumn{3}{|c|}{$P<0.05^{*} P<0.01^{* *}$} \\
\hline
\end{tabular}

The findings in table 2 reveal that for the present sample: Extraversion has a significant negative correlation with BMI. There is a significant positive correlation between Openness and BMI and a significant negative correlation between Conscientiousness and BMI. There also exists a significant positive correlation between anxious attachment in romantic relationships and BMI.

The findings in Table 3 indicate that for the total sample, Openness and Conscientiousness are significant predictors of BMI.

\section{DISCUSSION:}

For the present study, in case of Neuroticism, a significant difference has been found to exist between the Overweight and Obese groups, with the latter having a higher mean score. Individuals with a high degree of neuroticism are usually more likely to feel irritable, angry, sad, anxious and have difficulty in tolerating the frustration caused by not acting on their urges and maladaptive coping responses. In a series of clinical studies conducted on patients who had undergone bariatric surgery, ${ }^{18,19}$ a significantly higher score on 'neuroticism' was recorded compared to normal-weight controls. Hermann et.al, (1975)20 in his research found that obese individuals tend to be highly aroused, he attributed dieting or restricted eating as being partially responsible for this heightened arousal. Dieting may as well in many cases be anxiety provoking, acting as a stressor. ${ }^{20}$ Neuroticism also roughly corresponds with negative affectivity, which may be a form of internal pain and pressure that is reduced temporarily by certain self-soothing behaviours such as feeding and drinking. Reducing high negative affect by overeating to feel better and to calm the self temporarily may later cause shame and higher negative affect, driving more compulsive overeating behaviour and resulting in a vicious cycle of negative affect and food intake. This might in turn have an adverse effect on body weight. ${ }^{21}$

Table 3: Stepwise Multiple Regression Analysis (SMRA) showing criterion variable and predictor variable for the total sample $(\mathrm{N}=90)$

\begin{tabular}{|l|l|l|l|l|l|l|l|l|}
\hline Criterion & Predictor & $\mathrm{R}$ & $\begin{array}{l}\mathrm{R} \\
\text { Square }\end{array}$ & $\begin{array}{l}\text { Adjusted } \\
\text { R Square }\end{array}$ & $\begin{array}{l}\mathrm{F} \\
\text { Value }\end{array}$ & $\begin{array}{l}\text { Significance } \\
\text { Value }\end{array}$ & $\begin{array}{l}\text { Beta } \\
\text { Coefficient }\end{array}$ & $\begin{array}{l}\text { Durbin } \\
\text { Watson }\end{array}$ \\
\hline BMI & Openness & 4.24 & 0.180 & 0.110 & 2.567 & $0.035^{*}$ & 0.234 & 0.512 \\
\hline BMI & Conscientiousness & 0.216 & 0.047 & 0.036 & 4.293 & $0.041^{*}$ & -0.216 & 0.125 \\
\hline
\end{tabular}


Significant differences have also been found among the Normal Weight and Obese groups in the Extraversion dimension of personality traits, with the former having a higher mean score. Extraverts are outgoing in nature. Individuals high in Extraversion tend to have a willingness of taking part in outdoor activities, hence participating in physical activities and games, which in turn might help them to stay physically healthy and have a control over the body weight. Obese people are often bullied and humiliated because of their body weight, which naturally makes them self-conscious, hence they prefer having a smaller circle and not going out very often, they also feel conscious of working out in front of others or in common places like a gym/park. Literature shows that a great percentage of obese women also reported having to face moderate-to-extreme embarrassment in social situations, such as work, parties or community gatherings because of their weight. ${ }^{22}$

There are also significant differences with respect to the dimension of Openness, in between the Normal Weight and Overweight groups as well as the Normal Weight and Obese groups, with the obese group having the highest and normal weight group having the lowest mean scores respectively. Individuals with a high degree of openness, are usually more curious, innovative and entertain unconventional concepts. By contrast, individuals low in Openness are more rigid in their beliefs, conservative in their tastes and are behaviorally set in their lifestyle. Possible explanations for the present finding could include the role that openness to experience may play in people's willingness to try out all kinds and varieties of lifestyle, new food and drinks without adhering to fixed diet plans even though such dietary intake may in the long run have negative effects on their health. People who are low on openness tend to prefer routines and familiarity in their day to day living and are more inhibited in trying new things. Studies have found dietary disinhibition to be strongly associated with adult weight gain. ${ }^{23}$ However, in studies focusing on 'openness', no clear association between this parameter and overweight/obesity could be detected. ${ }^{4}$
Significant differences were also found between the Normal weight and Obese groups with respect to the dimension of Conscientiousness with the Normal weight and Obese groups having the highest and lowest mean scores respectively. The explanation for this is in the order and self-discipline facets of Conscientiousness which are strongly associated with body weight. ${ }^{4}$ Sincerely engaging in routine exercises and maintaining strict diets could be linked to the discipline factor of the conscientiousness dimension of personality that in turn results in having a lower adiposity.

The findings in this study also reveal that Extraversion has a significant negative correlation with BMI for the present sample. Similar findings were reported in a study conducted among Japanese participants where overweight groups scored lower on Extraversion. ${ }^{24}$ Obese and overweight individuals might limit their outgoing behaviour due to the stigma associated with body weight. ${ }^{25}$ In a population survey, more than one in five adults with obesity reported being embarrassed in social situations and feeling too fat to exercise. ${ }^{26}$ Hence due to the fear of facing embarrassment they start avoiding social situations and have a lower degree of extraversion.

The findings also show that there is a significant positive correlation between Openness and BMI. Some studies in the current literature do not find significant associations between openness and $\mathrm{BMI}^{4,27}$ while others have reported that high openness score was related to lower BMI. ${ }^{28}$

In the present study, conscientiousness has a negative correlation with BMI. Across different personality domains, samples, and in cases of both self-reported and clinician-assessed weight, individuals high on conscientious have shown lower adiposity. 4,27,28 The daily lifestyle habits of individuals high in Conscientiousness may have to role to play in contributing to their healthy weight. These individuals, for example, are physically active, ${ }^{10}$ are very disciplined and have a systematic lifestyle and refrain from binge eating and drinking. They follow a daily exercise regime and participate in physical activities that helps to keep their body weight in control. 
The present findings indicate that there exists a significant positive correlation between anxious attachment in romantic relationships and body mass index of the present sample. Attachment anxious individuals tend to experience poor emotional control (the hyperactivation of the attachment system leads individuals to focus on distressing attachment cues). ${ }^{29}$ Therefore, they tend to rely on external factors for emotional control- factors that act as temporary affect regulators, thus having the tendency to engage in disinhibited eating, and in turn, this mediator might promote an elevated body weight. $^{30}$ As a society that places a lot of emphasis on thinness as an important physical characteristic, young obese adults are likely to feel anxious about their body weights and may experience considerable difficulties achieving and maintaining close relationships. Overweight and obese individuals are commonly subjected to prejudice and discrimination. ${ }^{31,32}$ Intimate relationships are very often a common context for bias related to body weight. The literature records studies where college students rate heavy women as relatively unattractive, unlikely to be dating, unlikely to have a boyfriend or partner, sexually unskilled, and unworthy of

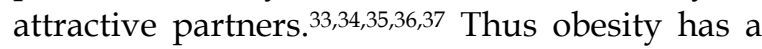
direct influence on the self concept and self esteem of individuals which in turn gets reflected in their romantic relationships too. Obesity has also been associated with a high degree of Neuroticism in individuals, which signifies that obese individuals might experience such feelings of anxiety in their romantic relationships too. Previous work demonstrated that individuals with higher degrees of attachment anxiety in their relationships are prone to increased binge eating. ${ }^{38}$

In this study, it was observed that the personality traits of Openness and Conscientiousness are significant predictors of high Body Mass Index which is a measure of obesity. Thus for the present sample, a high degree of openness and low conscientiousness are factors that play a significant role in weight gain.

\section{CONCLUSION:}

This study illustrates in depth the association that obesity has with our personality traits and how these traits can to an extent contribute to adiposity. The present study also adds to the literature on interpersonal problems in romantic relationships caused by weight stigma and further highlights the need for research and interventions to effectively battle this common, prevalent and harmful form of bias, which affects individuals in their day to day lives.

ACKNOWLEDGEMENT: None

FUNDING: None

\section{CONFLICT OF INTEREST: None}

\section{REFERENCES:}

1. Shukla NK, Shukla M, Agarwal D et al. Prevalence of overweight and obesity among adolescents in India: a systematic review. Int J Curr Res Rev.2016;18: 21-25.

2. Misra A, Chowbey P, Makkar BM. Consensus statement for diagnosis of obesity, abdominal obesity and the metabolic syndrome for Asian Indians and recommendations for physical activity, medical and surgical management. J Assoc Physicians India. 2009; 57:163-170.

3. Provencher V, Be'gin C, Gagnon-Girouard MP et al. Personality traits in overweight and obese women: Associations with BMI and eating behaviors. Eat Behav.2008; 9:294-302.

4. Terracciano A, Sutin AR, McCrae RR et al. Facets of personality linked to underweight and overweight. Psychosom Med.2009; 71: 682.

5. Gerlach G, Herpertz S, Loeber S. Personality traits and obesity: a systematic review. Obes Rev. 2015;16: 32-63.

6. Sutin AR, Ferrucci L, Zonderman $A B$ et al. Personality and obesity across the adult life span. I Pers Soc Psycho.2011;101: 579-587

7. Sutin AR, Terracciano A. Personality traits and body mass index: modifiers and mechanisms. Psychol Health.2016; 31: 259-275.

8. Jokela $M$, Hintsanen $M$, Hakulinen $C$ et al. Association of personality with the development and persistence of obesity: a meta-analysis based on individual-participant data. Obes Rev.2013; 14:315323.

9. Mukhopadhyay,S. Do women value marriage more? The effect of obesity on

cohabitation and marriage in the USA. Review of Economics of the Household. 2008; 6: 111-126.

10. Pearce MJ, Boergers J, Prinstein MJ. Adolescent obesity, overt and relational peer victimization and romantic relationships. Obes Res.2002;10: 386-393.

11. Butler SM, et al. Change in diet, physical activity, and body weight in female college freshman. Am J Health Behav. 2004; 28(1):24-32 
12. Poobalan A, Aucott, L.Obesity Among Young Adults in Developing Countries: A Systematic Overview. Curr. Obes. Rep. 2016; 5(1):2-13

13. Costa PT, McCrae RR. Normal personality assessment in clinical practice: the NEO Personality Inventory. Psychol. Assess. 1992; 4:5

14. Robins $R W$, Fraley $R C$, et al. A longitudinal study of personality change in young adulthood. J Pers. 2001; 69(4):617-40.

15. Costa P, McCrae RR. The Five-Factor Model and the NEO Inventories. Oxford Handbook of Personality Development. 2012; 299-322

16. Fraley RC, Waller NG, Brennan KA. An itemresponse theory analysis of self-report measures of adult attachment. J Pers Soc Psycho.2000;78: 350365.

17. Sibley CG, Fischer R, Liu JH. Reliability and validity of the revised experiences in close relationships (ECR$R)$ self-report measure of adult romantic attachment. Person.Soc.Psychol.Bull.2005;31:1524-1536

18. Wickramasekera I, Price DC. Morbid obesity, absorption, neuroticism, and the high risk model of threat perception. Am J Clin Hypn. 1997; 39: 291301.

19. Larsen JK, Geenen R, Maas C. Personality as a predictor of weight loss maintenance after surgery for morbid obesity. Obesity Research. 2004; 12:18281834.

20. Herman $C P$, Polivy J. Anxiety, restraint and eating behavior. J. Abnorm. Psychol. 1975; 84: 666-672

21. Wickramasekera I, Pope AT, Kolm P. On the Interaction of Hypnotizability and Negative Affect in Chronic Pain Implications for the Somatization of Trauma. The Journal of Nervous and Mental Medicine.1996; 628-635

22. Sarwer DB, Wadden TA, Foster GD. Assessment of body image dissatisfaction in obese women: specificity, severity and clinical significance. J. Consult. Clin. Psychol.1998; 66(4): 651-654

23. Intiful FD, Oddam EG, Kretchy I, et al. Exploring the relationship between the big five personality characteristics and dietary habits among students in a Ghanaian University. BMC Psychol. 2019; 7:10

24. Kakizaki M, Kuriyama S, Sato Y et al. Personality and body mass index: A cross-sectional analysis from the Miyagi Cohort Study. J Psychosom Res. 2008; 64: 7180.

25. Jackson SE, Steptoe A. Association between perceived weight discrimination and physical activity: a population-based study among English middle aged and older adults. BMJ. 2017;1: 45-92

26. Ball K, Crawford D, Owen N. Too fat to exercise? Obesity as a barrier to physical activity. Aust N Z J Public Health.2000; 24:331-333

27. Chapman BP, Fiscella $K$, Duberstein $P$ et al. Can the influence of childhood socioeconomic status on men's and women's adult body mass be explained by adult socioeconomic status or personality? Findings from a national sample. J Health Psychol.2009;28: 419.

28. Brummett BH, Babyak MA, Williams RB et al. NEO personality domains and gender predict levels and trends in body mass index over 14 years during midlife. J Res Pers. 2006;40: 222-236.

29. Mikulincer M. Adult attachment style and affect regulation: strategic variations in self-appraisals. J Pers Soc Psycho.1998; 75:420-435.

30. Baron RM, Kenny DA. The moderator-mediator variable distinction in social psychological research: conceptual, strategic, and statistical considerations. I Pers Soc Psycho. 1986; 51:1173-1182.

31. Puhl RM, Rebecca M, Janet D. Stigma, Obesity, and the Health of the Nation's Children. Psychol Bull.2000;133(4):557-558.

32. Latner JD, Janet D, Daria $S$ et al. Residual Obesity Stigma: An Experimental Investigation of Bias Against Obese and Lean Targets Differing in Weight Loss History. Obesity.2012; 20(10): 2035-2038.

33. Harris MB. Is love seen as different for the obese? J Appl Soc Psychol.1990; 20: 1209-1224.

34. Horsburgh-McLeod G, Latner JD, O'Brien K. Unprompted generation of obesity stereotypes. Eat Weight Disord. 2008; 14: 2-3

35. Regan PC. Sexual outcasts: The perceived impact of body weight and gender on sexuality. J Appl Soc Psychol.1996; 26: 1803-1815.

36. Tiggeman $M$, Rothblum ED. Gender differences in social consequences of perceived overweight in the United States and Australia. Sex Roles. 1988; 18: 7586.

37. Gortmaker SL, Must A, Perrin JM et al. Social and economic consequences of overweight in adolescence and young adulthood. N Engl J Med.1993; 329: 10081012.

38. Alexander KE, Siegel HI. Perceived hunger mediates the relationship between attachment anxiety and emotional eating. Eat Behav. 2013; 14(3): 374-377. 